\title{
Research on Practical Teaching Reform of Entrepreneurship Management Course
}

\author{
Zhao Jingfang \\ Ningbo Dahongying University, Ningbo 315175, China \\ zhaojf80@126.com
}

Keywords: Entrepreneurial Management; Teaching Reform; Practice

\begin{abstract}
With the deepening of China's reform and opening up and the development of the socialist market economy, the status and role of management science has been increasingly recognized and attracted the attention and attention of the whole society. To cultivate students' comprehensive quality and entrepreneurial innovation ability as the goal, to strengthen the management curriculum construction, continuous optimization and innovative teaching mode, education and teaching reform and development of the urgent requirements. Management curriculum construction and teaching model reform requires the establishment of correct guiding ideology; properly handle the relationship between disciplinary synthesis and differentiation, highlighting the basic and rational principles of management courses; focus on curriculum teaching objectives of innovative teaching model; standard syllabus, update and improve Teaching content to improve teaching methods, to strengthen the practical teaching links; reform teaching assessment methods to strengthen the quality of teaching control and evaluation; adhere to the combination of teaching and learning, theory and practice combined.
\end{abstract}

\section{Theoretical Introduction of Entrepreneurial Management Courses}

Entrepreneurship management as a professional school set up a basic course, mainly to teach students the entrepreneurial knowledge, training students entrepreneurial skills, which is a theoretical and practical combination of strong courses, cultivate entrepreneurship entrepreneurial education curriculum system of the core link, the goal is to enable students to accept entrepreneurship education at the same time, cultivate students' entrepreneurial awareness and innovative spirit, shaping the entrepreneurial characteristics and professionalism.

At present, there are some shortcomings in the teaching and learning of entrepreneurial management courses: the theory of teaching re-theory light practice, heavy knowledge of light ability, teaching methods and methods are relatively simple, on the other hand teachers do not have entrepreneurial experience, not involved in the enterprise business management process, For the entrepreneurial practice case experience is not deep, teaching focus and case core issues will be biased, so the case teaching effect is not obvious. Students in the learning process due to the lack of practical training, practical experience of the curriculum is not deep, and more to get credits for the purpose of the lack of entrepreneurial initiative. The reform and practice of the entrepreneurial management curriculum not only apply to the rationalization of the teaching of the entrepreneurial management curriculum, but also to the teaching guidance of all the specialized courses with the background of entrepreneurship education ${ }^{[1]}$.

In order to reform and explore the current curriculum teaching system, provide students with entrepreneurial practice training environment, stimulate students 'enthusiasm for learning and entrepreneurial spirit, cultivate students' innovative entrepreneurial ability, so that students with entrepreneurial awareness and innovative spirit, master the professional knowledge and basic of entrepreneurial knowledge and skills, with the opportunity to seize the opportunity to seize the opportunity to create performance and the potential of the cause. It can improve the teaching quality of entrepreneurship education and improve the quality of entrepreneurship training. 


\section{Problems in Entrepreneurship Management Teaching}

With the establishment of new professional and management of the professional category increased, entrepreneurial management courses also will be independent and more and more attention. However, due to the construction time of management course is not long, coupled with the objective conditions and limitations of experience, management education teaching there are many problems ${ }^{[2]}$. Fig.1 shows current situation and problems of entrepreneurship management teaching.

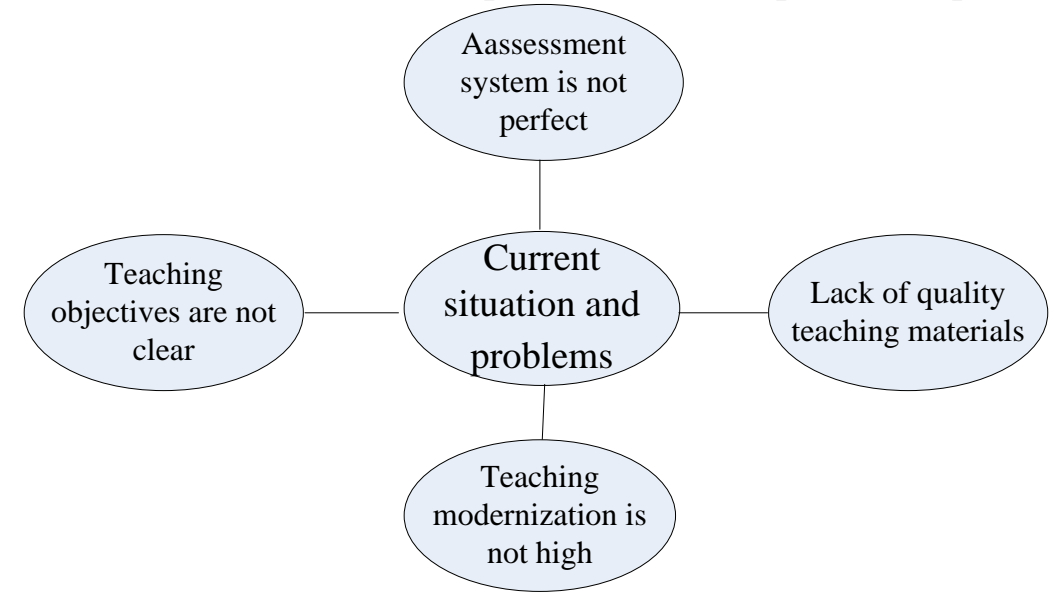

Fig. 1.Current situation and problems of entrepreneurship management teaching

For a long time, the status and role of entrepreneurial management teaching objectives in the teaching and teaching of higher education have not received due attention. Management teaching can only meet the needs of knowledge transfer. The cultivation of students' comprehensive quality and entrepreneurial innovation is not fully reflected. In the teaching methods, undergraduate management classroom teaching is basically based on teacher oral teaching, supplemented by blackboard, simple body language and teaching wall charts. As the teaching objectives are ambiguous, the teaching methods are relatively simple and rigid, the teaching methods are backward, the level of teaching modernization is not high, so that the way of knowledge transfer can't meet the needs of contemporary students and adapt to the needs of the development of the situation.

Teaching objectives was lack of quality teaching materials, affecting the students really grasped the real knowledge. The teaching material is the basic tool for students to review and master the scientific knowledge systematically. It is an auxiliary means to help students to consolidate and deepen their understanding of the knowledge they have learned in the classroom. In the context of popular education, the cultivation of talents can't be entirely dependent on the words and deeds in the classroom, monasteries, must be closely integrated with education and self-education. The evaluation system is not perfect, as well as teaching evaluation mechanism, teaching examination is an important part of teaching management. Scientific and reasonable and simple teaching evaluation system and perfect teaching evaluation mechanism are the important means to implement teaching control and teaching evaluation. Due to the imperfection of the teaching evaluation system and the imperfection of the teaching evaluation mechanism, it can't effectively mobilize the enthusiasm of teaching and learning, which has affected the teaching effect and the quality of personnel training to a certain extent ${ }^{[3]}$.

\section{Practical Teaching Reform Content}

At present, the content of management materials is strong, far away from the reality, most of the teaching content to the western management theory and practice as the core, the learning organization, the core competitiveness of enterprises, corporate reengineering and corporate social responsibility, etc. These have been proven very effective theory is not timely to absorb, and the development of reality is not suited. Therefore, in the teaching materials to increase those who have 
refined the management of modern problems, there is sublimation of management thinking ${ }^{[5]}$.

At present, the management class teaching theory and practice is clearly out of touch, most of the classroom teaching method is used to explain the basic principles plus a few vivid cases, so far can't meet the needs of students, nor cultivate practical ability of talent The In order to combine the theory and practice organically in the teaching, it must be liberated from the original framework. The teacher should lead the students to study the new situation and new problems in the development of the enterprise, study how to solve the problem from the manager's point of view, From the abstract interpretation to the specific, and then from the specific sublimation to the abstract, for the theoretical knowledge and practical use to build a bridge management courses are applied and comprehensive disciplines, so lectures need a large number of teaching cases, the case of choice on the lecture effect And the improvement of student ability has an important impact.

In the teaching process, through the environment, the conditions set to simulate the real situation, the arrangement of students self-learning tasks, to provide students with a development and exercise skills opportunities. The use of management software to develop students in the simulation environment under the environment to adapt to the application of management software in the process of using the knowledge learned to solve the software in a variety of practical problems in the intelligent software to enhance students' skills to develop students Analyze the problem and the ability to self-transcendence. Therefore, management courses should be increased targeted teaching cases. One should try to choose a modern case, to reduce the sense of distance from the students; the second is to try to use their own cases, to increase student familiarity; third is to increase the case of small and medium companies, which increase the intimacy of students These targeted cases will increase the desire of students to start and move.

\section{Teaching and Practice Platform Construction}

The importance of entrepreneurship management courses is becoming more and more prominent. Curriculum construction needs to keep pace with the times, constantly improve the overall quality of teachers, update teaching content in real time, change teaching ideas, improve teaching methods and teaching methods, promote teaching reform. Fig.2 shows teaching and practice platform.

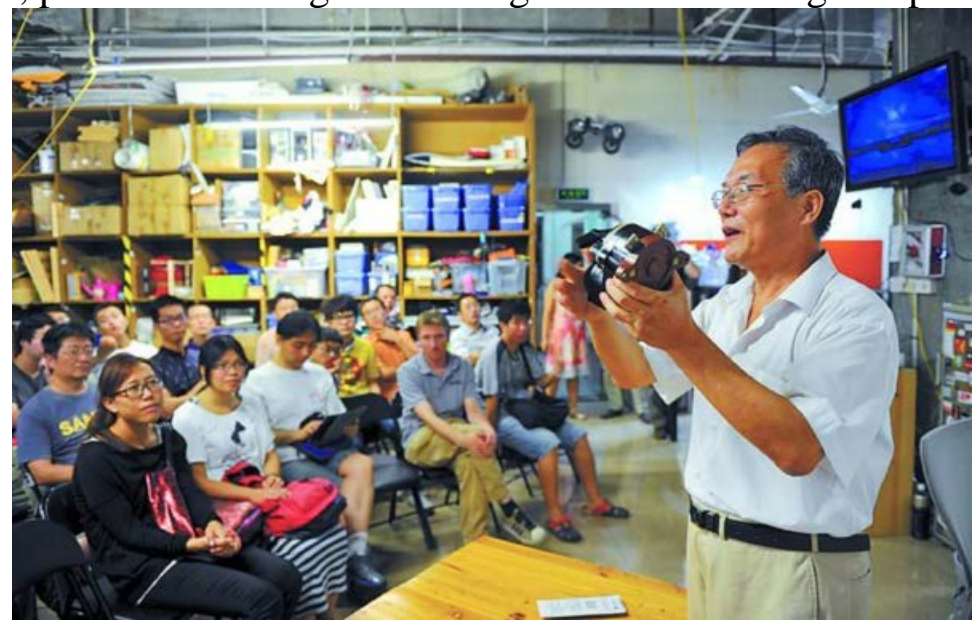

Fig. 2.The teaching and practice platform

Hire outside the instructor to participate in classroom teaching, make full use of all the favorable resources, and actively invite successful entrepreneurs or well-known entrepreneurs to hold lectures or seminars, so that students and entrepreneurs at zero distance, the real experience from the practice of first-line experience and experience, to stimulate students Entrepreneurial enthusiasm, to guide students' entrepreneurial intentions, to tap the potential entrepreneurial ability of students. Hire experts and scholars to set up theoretical frontier knowledge lectures, so that students understand the forefront of business management development and domestic and foreign enterprises management and operation. Organization of students to visit the enterprise, the actual site visits to help students on the entrepreneurial process have personal experience and understanding, to enhance students' sense of entrepreneurship, enrich the students entrepreneurial 
management knowledge.

Relying on the diversified practice platform, the college encourages students to form entrepreneurial team for entrepreneurial project, professional teachers and school tutors in the students to start the project research process to guide students, so as to provide students with entrepreneurial practice to provide hardware and software support. Entrepreneurship center is mainly through a large number of business entrepreneurship management practices, so that students experience entrepreneurship, training in business after the business management capabilities, so as to cultivate students' entrepreneurial ability, so that students have the entrepreneurial and management needs of the various knowledge and ability. The Entrepreneurship Management Team as much as possible to provide students with practical training platform: contact and arrange students to practice base practice; training entrepreneurial skills; hold entrepreneurial planning contest; carry out business plan contest.

\section{Conclusions}

Innovation and entrepreneurial ability training has always been the eternal theme of national development, college students is the main force of innovation and entrepreneurship, higher education institutions should take on this training task, especially the innovative ideas and actions into the classroom students. Entrepreneurship management practice as an important position in the enterprise core curriculum, it should shoulder to adapt to social and economic restructuring and development needs of the teaching reform. The reform of classroom teaching in colleges and universities should establish the goal of serving the society, pay attention to the cultivation of students' practical ability, optimize the teaching content in depth, enhance the practicality of classroom teaching, make flexible use of teaching methods and realize the comprehensive improvement of practical skills. Entrepreneurship management curriculum teaching content, teaching methods and other reform and practice, to mobilize students to learn the initiative, enthusiasm and entrepreneurial enthusiasm, cultivate students' self-awareness, participation in the spirit of consciousness and hard work, so that students have both entrepreneurial skills, pioneering, create the spirit and the consciousness of the times.

\section{Reference}

[1] Malan, Sheng Li qun, etc. Classroom teaching designs holistic orientation [M]. Hangzhou, Zhejiang Education Press, 2011.

[2] Wang Wenzhi, Sheng Qunli. The Connection between Meaning Learning and Teaching Mode A Perspective of Contemporary International Teaching Design[J]. Journal of Zhejiang International Studies University, 2012 (3).

[3] Wei Guochen, Yang Baohong Innovation and Practice Management Major in Universities Quality Management Teaching [J] Inner Mongolia Agricultural University: Social Sciences, 2012 (3).

[4] Ou Yang jie, research practice teaching system for innovation and entrepreneurship culture [D] Wuhan: Central China Normal University degree decadent force on disabilities, 2014.

[5] Zhao Yi. Some Thoughts of Teaching Reform flipped classroom Higher Economic Management Professional and based - Zhejiang Business Technology Institute example [J] Communication of Vocational Education, 2015 (12): 59-61. 